\title{
BEDA EFEK PEMBERIAN MOTOR RELEARNING PROGRAM DAN PEMBERIAN PROPRIOCEPTIVE NEUROMUSKULAR FACILITATION TERHADAP PENINGKATAN KEMAMPUAN FUNGSIONAL PENDERITA POST STROKE
}

\section{The difference effect of the motor relearning program and proprioceptive neuromuscular facilitation on the improvement of functional abilities of post-stroke patients}

\author{
Hasbiah, Hasnia Ahmad \\ Jurusan Fisioterapi Polteknik Kesehatan Makassar \\ Email: hasbiahfisiopoltekkes@gmail.com
}

\begin{abstract}
ABSTRAK
Perbedaan efek pemberian motor relearning program dan pemberian proprioceptive neuromuskular facilitation terhadap peningkatan kemampuan fungsional penderita post stroke. Penelitian ini mengangkat permasalahan Beda efek pemberian motor relearning program dan pemberian proprioceptive neuromuskular facilitation terhadap peningkatan kemampuan berjalan penderita post stroke. Jenis penelitian yang digunakan adalah Quasy-experimental dengan menggunakan desain penelitian two-group pretest posttest design. Teknik pengambilan sampel menggunakan teknik purposive sampling dengan jumlah sampel 26 orang yang dibagi dalam 2 kelompok masing-masing berjumlah 13 orang. Penentuan sampel berdasarkan kriteria inklusi dan eksklusi. Instrumen pengambilan data yang digunakan dalam penelitian ini adalah Barthe index. Penelitian ini dilakukan selama 3 bulan, 16 Juni - 16 September 2020. Tidak ada perbedaan pengaruh yang bermakna antara MRP dan PNF terhadap peningkatan aktivitas fungsional pada penderita. Keduanya baik digunakan dalam penanganan kondisi aktivitas fungsional akibat post stroke
\end{abstract}

Kata Kunci : Aktivitas Fungsional, Motor Relearning Program (MRP), Proprioceptive Neuromuskular Facilitation (PNF), Stroke

\section{ABSTRACT}

The difference effects of the motor relearning program and proprioceptive neuromuscular facilitation on improving the functional abilities of post-stroke patients. This study aims to determine the different effects of the motor relearning program and proprioceptive neuromuscular facilitation on the improvement of the ability to walk in post stroke sufferers. This type of research is Quasy-experimental using a two-group pretest-posttest design. The sampling technique used purposive sampling technique with a sample size of 26 people divided into 2 groups each of 13 people. The samples were determined based on inclusion and exclusion criteria. The data collection instrument used in this study was the Barthel index. This study was conducted for 3 months, 16 June - 16 September 2020. There was no significant difference between MRP and PNF on the increase in functional activity in patients. Both are good for handling functional activity problems due to post stroke

Keywords: Functional Activity, Motor Relearning Program (MRP), Proprioceptive Neuromuscular Facilitation (PNF), Stroke

\section{PENDAHULUAN}

Dengan Kemajuan teknologi dan pengaruh globalisasi telah mendorong terjadinya perubahan pola hidup pada setiap individu yang terlibat didalamnya. Teknologi telah memanjakan dan memudahkan manusia dalam pekerjaan dan kehidupan sehari-hari sehingga manusia malas bergerak dan beraktifitas. Sementara pengaruh globalisasi melalui informasi yang semakin mudah diperoleh memungkinkan masyarakat Indonesia, khususnya didaerah perkotaan, menganut gaya hidup modern, dengan mengkonsumsi makanan instan, minuman beralkohol, merokok, bekerja berlebihan, stres, dan kurang berolahraga.
Organisasi Kesehatan Dunia (WHO) mendefinisikan stroke sebagai suatu sindrom klinis dengan gejala berupa gangguan fungsi otak yang dapat menimbulkan kematian maupun kelainan yang menetap lebih dari 24 jam akibat gangguan vaskuler. Stroke adalah cedera vaskuler akut pada otak dimana serangan terjadi secara mendadak dan berat pada pembuluh darah otak yang mengakibatkan kematian jaringan otak secara permanen.

Berdasarkan data Riskesda Depkes (2013) stroke merupakan penyebab kematian utama di Indonesia dan prevalensi stroke di Indonesia 12,1 persen per 1.000 penduduk. Angka itu naik dibandingkan Riskesdas 2007 
yang sebesar 8,3 persen. Setiap tahunnya belasan juta orang didunia terkena stroke dan 5 juta diantaranya meninggal karena stroke. Angka ini diperkirakan akan semakin meningkat.

Di Amerika Serikat setiap tahunnya, 700 ribu warga Amerika mengalami stroke dan 160 ribu orang meninggal karenanya, sedangkan di Indonesia diperkirakan 500 ribu penduduk terkena stroke setiap tahunnya.

Widiyanto (2009) mengungkapkan bahwa $80 \%$ penderita stroke mempunyai defisit neuromotor sehingga memberikan gejala kelumpuhan sebelah badan dengan tingkat kelemahan bervariasi dari yang lemah hingga berat, kehilangan sensibilitas, kegagalan sistem koordinasi, perubahan pola jalan, hingga terganggunya keseimbangan.

Masalah-masalah yang ditimbulkan oleh stroke bagi kehidupan manusia sangatlah kompleks (Irfan, 2019). Sedangkan, bagi penderita stroke itu sendiri aktivitas berjalan merupakan hal yang sangat penting untuk mendukung aktivitas seharihari. Akibat adanya gangguan vital otak, maka penderita stroke melakukan aktivitas berjalan dengan pola yang abnormal.

Untuk melakukan aktivitas berjalan dan menyangga tubuh, kaki merupakan bagian penting tubuh, sehingga jika terjadi kelainan pada kaki maka aktivitas sehari-hari akan terhambat (Lestari, 2010). Adanya gangguan gaya gerak kaki bukan hanya menimbulkan kesulitan berjalan tetapi juga menyebabkan mudah lelah, mudah jatuh dan pola jalan yang abnormal.

Pergelangan kaki dan gerakan pangkal paha memainkan bagian penting dalam membentuk gaya jalan yang dihasilkan oleh yang otot-otot kaki. Penderita stroke kerap mengalami kesulitan melakukan (dorsofleksi). Hal ini akan mempengaruhi kemampuannya untuk melakukan aktivitas sehari-hari sehingga kualitas hidup penderita stroke menjadi tergantung pada orang lain (Musriyati et al., 2015).

Berbagai penelitian menunjukkan bahwa pelayanan stroke yang terorganisir dalam unit stroke akan menurunkan kematian, menurunkan angka kecacatan, dan memperbaiki status fungsional pasien stroke. Penelitian yang dilakukan pada 1484 pasien stroke menunjukkan bahwa ada perbedaan dalam pola pemberian anti platelet, anti koagulan, pelayanan fisioterapi dan terapi wicara antar berbagai pusat pelayanan stroke (Belda-Lois et al., 2011).

Menurut Sullivan et.al terapi latihan adalah metode yang paling umum digunakan untuk mengatasi masalah mobilitas fisik setelah kerusakan otak. Berbagai model terapi yang dapat diberikan pada pasien stroke seperti metode Rood, metode Johnstone, metode brunnstorm, metode bobath, metode Proprioceptive Neuromuscular Facilitation (PNF), dan metode Motor Relearning Programme (MRP) yang menggunakan pendekatan motor control dan motor learning.

MRP dikembangkan oleh Janet $\mathrm{H}$. Carr dan Roberta Shepherd pada sekitar tahun 1980an di Australia. Metode MRP merupakan program spesifik untuk melatih kontrol motorik spesifik dengan menghindarkan gerakan yang tidak perlu/salah serta melibatkan proses kognitif dan penerapan ilmu gerak.

Dalam metode MRP untuk melatih motorik, pasien harus melakukan gerakan sesuai dengan gerakan dasar terapi. Setiap gerakan-gerakan yang diterapkan tersebut memiliki maksud atau tujuan dan target yang berpengaruh pada pasien sehingga pasien itu sendiri tidak merasa sia-sia melakukan gerakan-gerakan tersebut. Tentu saja hal tersebut tidak terjadi secara instan, melainkan dibutuhkan latihan yang teratur dan berulang-ulang. Segala aktivitas atau gerak manusia yang terorganisasi akan lebih baik dan lebih efektif karena latihan (Wirawan, 2009). Dalam metode MRP, latihan yang efektif adalah: latihan aktif, aktivitas spesifik, dan variasi latihan. Semua latihan ini akan membantu penderita stroke dalam mengembalikan kekuatan otot dan melatih saraf motorik berkoordinasi kembali dengan otak.

Latihan tersebut dapat memberikan proses pembelajaran aktivitas fungsional serta menerapkan premis dasar bahwa kapasitas otak mampu untuk reorganisasi dan beradaptasi sebagai kemampuan plastisitas otak dan dengan latihan yang terarah dapat saja menjadi sembuh dan membaik, selain itu sebagai relearning kontrol motorik sehingga dapat mengeliminasi gerakan yang tidak diperlukan 
dan meningkatkan kemampuan pengaturan postural dan gerakan (Irfan, 2019).

Sedangkan PNF adalah konsep treatment, filosofi yang mendasarnya adalah bahwa semua manusia termasuk yang mengalami disabilitas memiliki potensi yang belum dimanfaatkan (Adler et al., 2007). PNF adalah salah satu konsep penanganan yang terkenal di kalangan fisioterapi sejak 1940. Dr. Kabat dan Margaret (Maggie) Knot memulai dan meneruskan untuk membuat dan mengembangkan tehnik dan prosedur penanganan setelah pindah ke Vallejo, California pada tahun 1947. Setelah Dorothy Vass bergabung kedalam tim pada tahun 1953, Maggie dan Dorothy menulis buku PNF pertama, publikasi 1956.

Hal ini menarik perhatian penulis untuk melakukan penelitian mengenai beda pengaruh penerapan MRP dan PNF terhadap peningkatan kemampuan fungsional pada pasien post stroke Non Hemoragic Stroke.

\section{METODE}

\section{Desain dan Waktu Penelitian}

Penelitian merupakan penelitian quasi eksperimen yaitu penelitian percobaan semu yang menggunakan kelompok pembanding terhadap kelompok yang akan diteliti, dimana terdapat 2 kelompok sampel yang akan diteliti untuk melihat perlakuan atau intervensi mana yang lebih baik atau lebih efektif.

Penelitian dilaksanakan pada 16 Juni - 16 September 2020 di RSKD Dadi Makassar

\section{Populasi dan Sampel}

Populasi penelitian adalah semua pasien post stroke yang datang berkunjung di Poliklinik Fisioterapi RSKD Dadi Makassar selama penelitian berlangsung. Sampel penelitian adalah 26 pasien post stroke yang memenuhi kriteria inklusi dan eksklusi yang besarnya ditentukan berdasarkan kriteria inklusi pasien yang menderita post stroke baik HS ataupun NHS, berusia 25 - 60 tahun, dan bersedia menjadi responden. Kriteria ekslusi post stroke diakibatkan oleh faktor keganasan seperti, Tumor dll. dan atau tidak mengalami gangguan fungsional

\section{Instrumen Pengumpulan Data}

Pengumpulan data melalui data primer yaitu peneliti langsung mengambil data dengan cara mengukur kemampuan fungsional dengan Barthel Index (data pre test dan post tes) dan melalui pengambilan data sekunder yaitu data dari medical record (catatan rekam medik) pasien atau responden.

Alat atau instrumen yang digunakan untuk mempermudah proses pengumpulan data dalam penelitian ini adalah pengukuran kemampuan fungsional dengan Barthel Index (data pre test dan post tes).

\section{Analisa Data}

Teknik pengolahan dan analisa data menggunakan bantuan program SPSS (Statistical Product For Service Solution) dengan Uji Non Parametrik.

\section{HASIL}

Penelitian ini menggunakan jenis penelitian quasi eksperimental dengan mengguankan desain pre-post test two group design. Penelitian ini dilakukan di Poli fisioterapi RSKD Dadi Makassar dan diperoleh 26 sampel, yang terdiri dari 13 orang kelompok perlakuan dengan MRP dan 13 orang kelompok perlakuan dengan PNF. Alat ukur yang digunakan untuk mengevaluasi aktivitas fungsional adalah index barthel dimana instrumen ini menggunakan skor 0-100.

Intervensi yang diberikan kepada sampel, untuk kelompok perlakuan satu adalah MRP sedangkan untuk kelompok perlakuan dua adalah PNF. Sebelum dilakukan intervensi terlebih dahulu dilakukan pretest untuk menilai intensitas aktivitas fungsional sebelum diberikan perlakuan. Intervensi diberikan 2 kali seminggu selama 4 minggu, dan pada intervensi terakhir dilakukan pengukuran kembali untuk menilai perubahan aktivitas fungsional sebagai hasil dari post test.

Tabel 1 menunjukkan bahwa pasien yang menderita untuk kelompok perlakuan dengan MRP terdapat laki-laki sebanyak 8 orang $(61,5 \%)$ dan perempuan sebanyak 5 orang $(38,5 \%)$. terdapat laki-laki sebanyak 8 orang $(61,5 \%)$ dan perempuan sebanyak 5 orang $(38,5 \%)$.

Tabel 2 menunjukkan bahwa pasien pada kelompok perlakuan dengan MRP yang paling banyak adalah kelompok umur kurang dari 60 tahun (lansia) sebanyak 7 orang 
(53,8\%). Sedangkan pada kelompok perlakuan dengan PNF yang paling banyak adalah kelompok kurang dari 60 tahun (dewasa) sebanyak 10 orang $(76,7 \%)$.

Tabel 3 menunjukkan bahwa pemberian MRP didapatkan mean nilai pretest sebesar 21,69 $\pm 11,456$, dan nilai post test sebesar 46,15 $\pm 22,912$, dan nilai $p$ sebesar 0,001 atau <0,05. Hal ini dapat dijelaskan bahwa pemberian MRP didapatkan mean nilai pretest sebesar 21,69 $\pm 11,456$, dan nilai post test sebesar $46,15 \pm$ 22,912, dan nilai $p$ sebesar 0,001 atau < 0,05 .

Tabel 4 menunjukkan bahwa bahwa pemberian PNF didapatkan mean nilai pretest sebesar $26,00 \pm 17,607$, nilai posttest sebesar 44,31 $\pm 17,878$, dan nilai $p=0,001$ atau <0,05. Artinya pemberian PNF mempunyai pengaruh terhadap peningkatan aktivitas fungsional.

Tabel 5 menunjukkan bahwa hasil uji Mann Whitney untuk pengujian hipotesis, mulai dari nilai post Index Barthel diperoleh nilai $p=0,650>0,005$ yang berarti bahwa tidak ada perbedaan pengaruh yang signifikan antara pemberian MRP dengan PNF. Namun pada selisih rata-rata peningkatan aktivitas fungsional, pemberian MRP lebih baik dibandingkan PNF.

\section{PEMBAHASAN}

MRP ini merupakan suatu program spesifik untuk melatih kembali kontrol motorik spesifik dengan mnghindarkan gerakan yang tidak perlu salah. Latihan ini melibatkan proses kognitif dan penerapan ilmu gerak. Dengan melatih kembali control motoric yang berdasarkan pemahaman tentang kinematika dan kinetika gerakan normal, kontrol dan latihan motorik (Braun, 2010). Latihan tersebut dapat memberikan proses pembelajaran aktivitas fungsional serta menerapkan premis dasar bahwa kapasitas otak mampu untuk reorganisasi dan beradaptasi (plastisitas otak) dan dengan latihan yang terarah dapat saja menjadi sembuh dan membaik, selain itu sebagai relearning kontrol motorik sehingga dapat mengeliminasi gerakan yang tidak diperlukan dan meningkatkan kemampuan pengaturan postural dan gerakan (Wirawan, 2009).
Hasil pengujian hipotesis dengan menggunakan uji Wilcoxon diperoleh hasil yang menunjukkan pemberian MRP dapat memberikan peningkatan aktivitas fungsional pada penderita. Aktivitas fungsional pada penderita mengalami peningkatan yang bervariasi, hal ini disebabkan karena setiap sampel memiliki aktivitas yang berbeda setelah di berikan intervensi dimana hal ini tidak dapat dikontrol dalam penelitian ini. Pada sampel yang mengalami peningkatan aktivitas fungsional yang besar terjadi karena penderita lebih kooperatif melaksanakan intervensi dan home program yang diberikan. Hasil pengujian hipotesis dengan menggunakan uji Wilcoxon diperoleh hasil yang menunjukkan pemberian PNF dapat memberikan peningkatan aktivitas fungsional pada penderita. Aktivitas fungsional pada penderita mengalami peningkatan yang bervariasi, hal ini disebabkan karena setiap sampel memiliki aktivitas yang berbeda setelah di berikan intervensi dimana hal ini tidak dapat dikontrol dalam penelitian ini. Pada sampel yang mengalami peningkatan aktivitas fungsional yang besar terjadi karena penderita lebih kooperatif melaksanakan intervensi dan home program yang diberikan.

PNF merupakan intervensi pengobatan yang paling sering digunakan dalam rehabilitasi neurologis. PNF dapat digunakan untuk meningkatkan performa dari tugas/aktivitas fungsional melalui peningkatan strength, fleksibilitas, dan ROM. Integrasi dari pencapaian ini dapat membantu pasien untuk : (1) membentuk kontrol kepala dan trunk, (2) memulai dan mempertahankan gerakan, (3) mengontrol pergeseran pusat gravitasi tubuh, dan (4) mengontrol pelvis dan trunk dalam midline tubuh sementara ekstremitas bergerak (Smeltzer \& Bare, 2002).

Hasil penelitian menunjukan bahwa setelah dilakukan intervensi untuk kedua kelompok, aktivitas fungsional yang dialami sampel tidak benar-benar hilang atau sembuh, diakibatkan karena adanya beberapa faktor yang tidak dapat dikontrol oleh peneliti seperti level aktivitas yang dilakukan oleh setiap sampel.

Akan tetapi hasil pengujian hipotesis dengan menggunakan uji mann-whitney diperoleh hasil yang menunjukkan tidak ada yang lebih efektif antara intervensi MRP 
dengan PNF terhadap perbaikan aktivitas fungsional pada penderita. Kedua kelompok tersebut memiliki efek terapeutik yang sama yaitu meningkatkan aktivitas fungsional

\section{KESIMPULAN DAN SARAN}

Pemberian intervensi MRP meningkatkan aktivitas fungsional pada penderita post stroke, pemberian intervensi PNF meningkatkan aktivitas fungsional pada penderita post stroke, tidak ada perbedaan pengaruh yang bermakna antara MRP dan PNF terhadap peningkatan aktivitas fungsional pada penderita. Keduanya baik digunakan dalam peningkatan aktivitas fungsional pada penderita post stroke. Saran yang dapat dikemukakan oleh peneliti adalah sebagai berikut : Masalah aktivitas fungsional yang terjadi akibat post stroke dapat diatasi oleh fisioterapi berupa PNF maupun MRP, sebaiknya dalam melakukan penelitian lebih memperhatikan homogenitas responden agar hasil yang diperoleh menjadi lebih baik serta memilih responden yang lebih dapat terkontrol agar hasil yang diperoleh lebih nyata.

\section{DAFTAR PUSTAKA}

Adler, S. S., Beckers, D., \& Buck, M. (2007). PNF in practice: an illustrated guide. Springer.

Belda-Lois, J.-M., Mena-del Horno, S., Bermejo-Bosch, I., Moreno, J. C., Pons, J. L., Farina, D., Iosa, M., Molinari, M., Tamburella, F., \& Ramos, A. (2011). Rehabilitation of gait after stroke: a review towards a top-down approach.
Journal of Neuroengineering and Rehabilitation, 8(1), 66.

Braun, S. M. (2010). Motor learning in neurological rehabilitation: practising skills with movement imagery. Datawyse/Universitaire Pers Maastricht.

Depkes, R. I. (2013). Riset Kesehatan Dasar (RISKESDAS) Dalam laporan nasional, badan penelitian dan pengembangan kesehatan. Departemen Kesehatan Republik Indonesia, Jakarta.

Irfan, M. (2019). Fisioterapi bagi insan stroke.

Lestari, N. K. (2010). Pengaruh Massage dengan Minyak Kelapa terhadap Pencegahan Dekubitus pada Pasien Stroke di Rumah Sakit Pusat Angkatan Darat Gatot Subroto Jakarta Pusat. Universitas Pembangunan Nasional Veteran: Jakarta.

Musriyati, I., Armiyati, Y., \& SN, M. S. A. (2015). Efektivitas Antara Range Of Motion Hook Grip Dan Lateral Prehension Grip Terhadap Peningkatan Luas Gerak Sendi Jari Tangan Pada Pasien Stroke Non Hemoragik Di RSUD Tugurejo Semarang. Karya IImiah.

Smeltzer, S. C., \& Bare, B. G. (2002). Buku Ajar Keperawatan Medikal-Bedah, Vol. 3.

Widiyanto. (2009). Terapi Gerak Bagi Penderita Stroke. Medikora, 1, 152661.

Wirawan, R. P. (2009). Rehabilitasi stroke pada pelayanan kesehatan primer. Majalah Kedokteran Indonesia, 59(2), 61-71. 
Tabel 1.

Distribusi responden berdasarkan jenis kelamin di RSKD Dadi Makassar

\begin{tabular}{lcccc}
\hline Jenis Kelamin & \multicolumn{2}{c}{$\begin{array}{c}\text { Kelompok Perlakuan } \\
\text { MRP }\end{array}$} & \multicolumn{2}{c}{ Kelompok Perlakuan PNF } \\
\cline { 2 - 5 } & $\mathrm{f}$ & $\%$ & $\mathrm{f}$ & $\%$ \\
\hline Laki-laki & 8 & 61,5 & 8 & 61,5 \\
Perempuan & 5 & 38,5 & 5 & 38,5 \\
\hline Total & 13 & 100,0 & 13 & 100,0 \\
\hline Sumber : Data Primer & \multicolumn{4}{c}{}
\end{tabular}

Tabel 2.

Distribusi responden berdasarkan kelompok umur di RSKD Dadi Makassar

\begin{tabular}{lcccc}
\hline Kelompok Umur & \multicolumn{2}{c}{$\begin{array}{c}\text { Kelompok Perlakuan } \\
\text { MRP }\end{array}$} & \multicolumn{2}{c}{ Kelompok Perlakuan PNF } \\
\cline { 2 - 5 } & $\mathrm{f}$ & $\%$ & $\mathrm{f}$ & $\%$ \\
\hline Kurang dari 60 tahun & 7 & 53,8 & 10 & 76,7 \\
60 tahun keatas & 6 & 46,2 & 3 & 27,1 \\
\hline Total & 13 & 100,0 & 13 & 100,0 \\
\hline
\end{tabular}

Sumber : Data Primer

Tabel 3.

Nilai aktualitas aktivitas fungsional penderita post stroke sebelum dan sesudah pemberian MRP di RSKD Dadi Makassar

\begin{tabular}{cccc}
\hline Pengukuran aktivitas fungsional & mean & SD & $\mathrm{p}$ \\
\hline Pre test & 21,69 & 11,456 & \\
\hline Post test & 46,15 & 22,912 & 0,001 \\
\hline
\end{tabular}

Ket : uji Wilcoxon

Tabel 4

Nilai aktualitas aktivitas fungsional pasien sebelum dan sesudah pemberian PNF di RSKD Dadi Makassar

\begin{tabular}{cccc}
\hline Pengukuran aktivitas fungsional & mean & SD & $p$ \\
\cline { 1 - 3 } Pre test & 26,00 & 17,607 & \\
\cline { 1 - 3 } Post test & 44,31 & 17,848 & 0,001 \\
\hline
\end{tabular}

Ket : uji Wilcoxon

Tabel 5 .

Analisis perbandingan nilai aktualitas aktivitas fungsional pasien antar kelompok MRP dengan kelompok PNF

\begin{tabular}{|c|c|c|c|}
\hline Pengukuran & Mean & SD & $P$ \\
\hline $\begin{array}{l}\text { Selisih pretes dan post } \\
\text { test MRP }\end{array}$ & 24,46 & 18,764 & 0.650 \\
\hline $\begin{array}{l}\text { Selisih pretes dan post } \\
\text { test PNF }\end{array}$ & 18,31 & 8,939 & \\
\hline
\end{tabular}


Tabel 1.

Distribusi responden berdasarkan jenis kelamin di RSKD Dadi Makassar

\begin{tabular}{ccc}
\hline Jenis Kelamin & f & Persentase \\
\hline Laki-laki & 8 & 40,0 \\
Perempuan & 12 & 60,0 \\
\hline Total & 20 & 100,0 \\
\hline Sumber : Data Primer & &
\end{tabular}

Tabel 2.

Distribusi responden berdasarkan umur di RSKD Dadi Makassar

\begin{tabular}{ccc}
\hline Jenis Kelamin & $F$ & Persentase \\
\hline Kurang dari 60 tahun & 9 & 45,0 \\
60 tahun keatas & 11 & 55,0 \\
\hline Total & 20 & 100,0 \\
\hline Sumber : Data Primer & &
\end{tabular}

Tabel 3.

Nilai aktualitas nyeri pasien low back pain sebelum dan sesudah pemberian MET dan MWD di RSKD Dadi Makassar

\begin{tabular}{cccc}
\hline Pengukuran nyeri & mean & SD & $p$ \\
\hline Pre test & 5,9 & 1,02 & 0,000 \\
\hline Post test & 3,45 & 0,82 & \\
\hline
\end{tabular}

Ket : wilcoxon test 